\title{
The first detection of a population of Aedes aegypti in the Atlantic Forest in the state of Rio de Janeiro, Brazil
}

\author{
Jeronimo Alencar $^{1 *}$, Cecília Ferreira de Mello ${ }^{1,2}$, Anthony Érico Guimarães ${ }^{1}$, \\ Daniele de Aguiar Maia ${ }^{1,3}$, Valdir de Queiroz Balbino ${ }^{3}$, Moisés Thiago de Souza Freitas ${ }^{3}$ \\ and Carlos Brisola Marcondes ${ }^{4}$
}

${ }^{1}$ Diptera Laboratory, Oswaldo Cruz Institute (Fiocruz), Rio de Janeiro, Brazil; ${ }^{2}$ Postgraduate Program in Animal Biology, Institute of Biology, Federal Rural University of Rio de Janeiro, Rio de Janeiro, Brazil; ${ }^{3}$ Bioinformatics and Evolutive Biology Laboratory, Department of Genetics, Federal University of Pernambuco, Recife, Pernambuco, Brazil; ; Department of Microbiology Immunology and Parasitology, Center of Biological Sciences, Federal University of Santa Catarina, Florianópolis, Santa Catarina, Brazil

Received for publication: 14 May 2020; Accepted for publication: 2 October 2020.

\begin{abstract}
Aedes aegypti is almost completely restricted to human-modified environments, especially urban areas, and rarely invades forests. Ovitraps were utilized in a reserve (Bom Retiro) in Rio de Janeiro state. Eggs of A. aegypti, genetically not differentiable from those of urban mosquitoes, were obtained at a location more than $700 \mathrm{~m}$ inside the border of the forest and $900 \mathrm{~m}$ away from a trail at the entrance to the forest. The presence of $A$. aegypti in a primary forest indicates its ability to adapt to sylvatic environments in Brazil, suggesting great potential for the transmission of several arboviruses due to the difficulty in controlling these mosquitoes.
\end{abstract}

Key words: Aedes aegypti; Atlantic forest; sylvatic habitat; yellow fever.

\section{Short communication}

Aedes aegypti aegypti (Linnaeus, 1762), generally termed Aedes aegypti, is easily differentiated from A. aegypti formosus (Walker, 1848), a sylvatic form present only in subSaharan areas. Because of good adaptation to man-made vessels (bottles, tires, water tanks, etc.), resistance of the eggs to desiccation, and preference for human blood, A. aegypti has now become widely distributed in all continents except Antarctica. It was probably transported to the American continent in water barrels on trading and slave ships.

Considering that $A$. aegypti is well adapted to human-modified environments, it has not shown the ability to disperse to sylvatic environments on the American continent and has rarely been found close to forest borders in Rio de Janeiro. This is in contrast to Aedes albopictus (Scuse, 1894), which is widely dispersed $(1000 \mathrm{~m})$ in forest environments (Lourenço-de-Oliveira et al. 2004). Immature forms of $A$. aegypti have been listed in nat-

\footnotetext{
*Corresponding author. E-mail: jalencar@ioc.fiocruz.br
}

${ }^{\circ}$ Copyright: the Author(s), 2020 | Licensee PAGEPress, Italy 
ural breeding sites on the American continent, mostly on islands; however, their presence inside forests, far from the forest border, and in human-modified environments has not been reported.

Chikungunya was recently found in sylvatic environments in Natal (Rio Grande do Norte) (Ximenes et al. 2020), and Zika in several sylvatic reservoirs in the American continent (Wastika et al. 2019). Aedes aegypti has been shown to be an efficient urban vector of several arboviruses (Marcondes and Ximenes 2016) and may also become a vector in sylvatic environments.

Here, we report the occurrence of $A$. aegypti in a preserved forest in the Brazilian state of Rio de Janeiro, far inside the forest border.

Ethics statement. The permanent license for collecting, capturing and transporting zoological material in the Bom Retiro Natural Heritage Private Reserve (RPPNBR) was granted by the Secretariat of the Environment and Agriculture (SISBIO) under number 34911-1 and dated 14/06/2012 in all national territory.

Bom Retiro Private Reserve of Natural Patrimony (RPPNBR) is located at the Macaé basin. The vegetation comprises dense ombrophilous sub-mountain forests, with median and advanced stages of regeneration, producing a tropical, wet climate. Geographical coordinates of the sampling sites were obtained using a Garmin GPS map (60CS GPS).

Mosquito collections were conducted in October 2015 and February 2016, using oviposition traps (ovitraps) consisting of lidless, $1 \mathrm{~L}$, matte black pots, with four $2.5 \times 14 \mathrm{~cm}$ plywood panels (Eucatex ${ }^{\circledR}$ boards) fastened vertically inside the trap using clips. These plates were replaced twice a month for examination in the laboratory. Fifteen ovitraps were installed in trees $2 \mathrm{~m}$ above the ground by hoisting the traps up the chosen trees using a nylon rope. The traps were monitored biweekly. All panels were sequentially numbered, placed in a humid container, and sent to the Diptera Laboratory of the Oswaldo Cruz Institute. Plates with mosquito eggs were immersed in transparent trays filled with MilliQ ${ }^{\circledR}$ water and maintained at $28 \pm 1{ }^{\circ} \mathrm{C}$. To imitate a more natural ecosystem, natural filtered water and leaf litter were added to the pots. The eggs were reared in the Diptera Laboratory, Oswaldo Cruz Foundation, and the adults obtained were identified according to previously generated keys (Consoli and Lourenço-de-Oliveira 1993, 1994).

Molecular analysis. We performed DNA extraction, PCR, and sequencing mitochondrial markers of 30 specimens of $A$. aegypti using Cytochrome Oxidase I (Zhao et al. 2009) (DNA Barcodes 16 and 14 from the urban (Nova Iguassu, Rio de Janeiro) and sylvatic habitats, respectively) and Cytochrome B (Hebert et al. 2003) (CytB 13 and 17 from the urban and sylvatic habitats, respectively). Only sequences with a PHRED score above 30 were used in the analysis. A contig assembly was carried out using CodonCode Aligner (CodonCode Corporation). Local alignments were done using BLAST (Altschul et al. 1990). All new sequences produced in this study were deposited in GenBank under accession numbers KU936133 to KU936192.

Nucleotide sequences were aligned using Muscle incorporated with MEGA v. 5.0 [13rozas]. Phylogenetic relationships among the sequences were inferred using neighbor-joining algorithms (MEGA v. 5.0) [7]. Aedes albopictus and Ochlerotatus taeniorhynchus (Wiedemann, 1821) (DNA Barcode) and A. albopictus and Haemagogus janthinomys (Dyar, 1921) (CytB) were selected as outgroups in the phylogenetic analysis. Pairwise nucleotide sequence divergences were estimated using K2P distance incorporated with MEGA v. 5.0 (Tamura et al. 2011).

Genetic diversity. Intrapopulation genetic diversity was assessed in terms of haplotype and nucleotide diversities, $\mathrm{K}$ values (number of genetic groups), and number of 
polymorphic sites using DnaSP v. 4.0 (Rozas et al. 2003). Genetic differentiation was assessed using the fixation index $F_{\text {st }}$ (Rozas et al. 2003).

Forty-two adult $A$. aegypti were collected from point RPPNBR-4 at the border of the forest and $778.9 \mathrm{~m}$ from point RPPNBR-3. Point RPPNBR-3 was situated $828.9 \mathrm{~m}$ from the border of the village and $928.9 \mathrm{~m}$ from where $A$. aegypti was found in 2003 . Figure 1 illustrates the locality, collection points, and distances between them. In addition, Table 1 shows the abundance of Haemagogus leucocelaenus (Dyar \& Shannon, 1924) (474), H.

Table 1. Absolute values $(\mathrm{N})$ of mosquitoes captured in the three areas of study at Bom Retiro Private Reserve of Natural Patrimony (RPPNBR), Rio de Janeiro, Brazil.

\begin{tabular}{llllccc} 
Species/sites & 1 & 2 & 3 & 4 & 5 & Total \\
Aedes aegypti & 0 & 0 & 0 & 42 & 0 & 42 \\
\hline Aedes albopictus & 3 & 7 & 0 & 0 & 0 & 10 \\
\hline Haemagogus leucocelaenus & 0 & 0 & 0 & 422 & 52 & 474 \\
\hline Haemagogus janthinomys & 0 & 0 & 0 & 6 & 2 & 8 \\
\hline Total & 3 & 7 & 0 & 470 & 54 & 534 \\
\hline
\end{tabular}

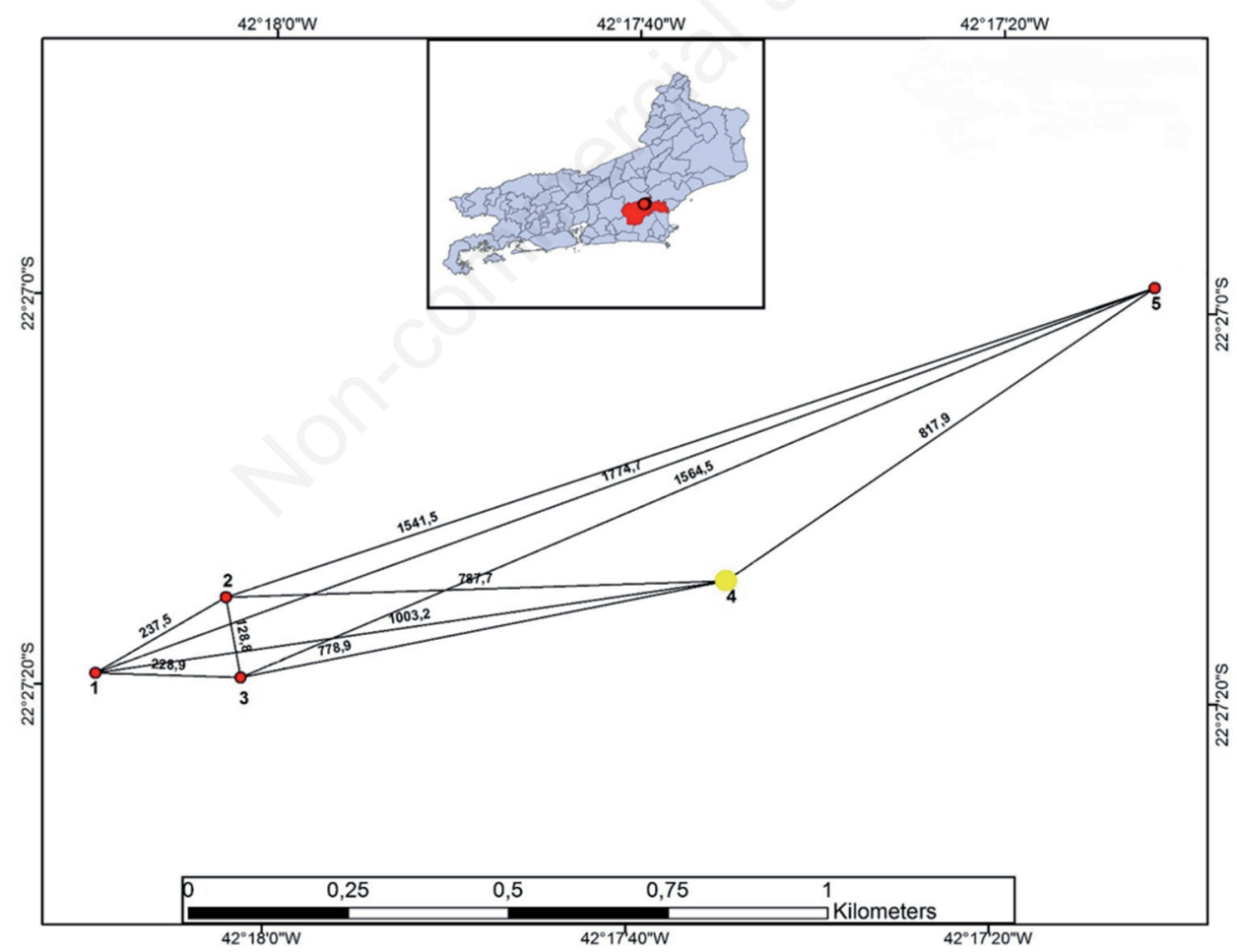

Figure 1. Sites in Bom Retiro Private Reserve of Natural Patrimony (RPPNBR), state of Rio de Janeiro, Brazil. 1, entry to the reserve, $22^{\circ} 27^{\prime} 19.4^{\prime \prime} \mathrm{S} 42^{\circ} 18^{\prime} 09.5^{\prime \prime} \mathrm{W} ; 2$, administration of reserve, $22^{\circ} 27^{\prime} 15.4^{\prime \prime} \mathrm{S} ; 42^{\circ} 18^{\prime} 02.4^{\prime \prime} \mathrm{W} ; 3$, entry to the forest, $22^{\circ} 27^{\prime} 19.5^{\prime} \mathrm{S} 42^{\circ} 18^{\prime} 01.5^{\prime \prime} \mathrm{W}$; 4 , positive for Aedes aegypti, $22^{\circ} 27^{\prime} 14.1^{\prime \prime} \mathrm{S} 42^{\circ} 17^{\prime} 34.9^{\prime \prime} \mathrm{W} ; 5$, an additional site for trapping more specimens of A. aegypti, $22^{\circ} 27^{\prime} 19.4^{\prime \prime} \mathrm{S} 42^{\circ} 18^{\prime} 09.5^{\prime \prime} \mathrm{W}$. 
janthinomys, and A. albopictus (10) obtained from ovitraps. Traps containing A. aegypti were situated $790 \mathrm{~m}$ from the entrance to the park (Figure 1); the forest is located $830 \mathrm{~m}$ from the nearest quarter of the village and $930 \mathrm{~m}$ from where A. aegypti was found in 2003.

Aedes aegypti collected from the ovitraps could not be differentiated morphologically or phylogenetically from those collected in the urban environment. The neighbor-joining analysis did not indicate a phylogenetic divergence between the laboratory and sylvatic populations of $A$. aegypti, revealing a single clade for $A$. aegypti when using DNA Barcode and CytB markers. This result indicates that the urban and sylvatic populations are related evolutionarily. Genetic distances, as determined by the K2P intraspecific values, ranged between 0 and 1\%. Intrapopulational analyses of $A$. aegypti specimens revealed a lower level of nucleotide and haplotype diversities in the laboratory and sylvatic populations (Table 2). In addition, the sylvatic and urban populations exhibited no significant genetic differences based on the $F_{\mathrm{st}}$; this reflects the absence of genetic divergence between the $A$. aegypti populations studied.

In the forest, $A$. aegypti was found far inside the border of the forest and far away from the village. The sporadic entry of workers into the forest did not indicate that mosquitoes were following them and feeding only on human beings. Additional studies on the attraction to several hosts and blood-feeding sources, and a search for immature forms of $A$. aegypti in natural habitats need to be conducted. The findings in this study emphasize the plasticity of $A$. aegypti, which could not be detected by the molecular techniques utilized. The preference of $A$. aegypti for human blood, possibly linked to its paucity in isoleucine, does not signify a restriction to this type of blood.

Although the number of eggs obtained in the sampling sites of this study was less than the number found inside the forest reserve, there is a minute possibility that a female could move from the human-modified environments, several hundreds of meters away, or even be transported by trucks in the forest, indicating that a population exists in the forest. In the description of an "artificial tree hole," A. aegypti was found in the "tropical forest" at El Verde, Puerto Rico, but no details were provided about the forest besides the location of the place of collection, which was two miles from the nearest village. Mangudo et al. (2015) listed many natural habitats for immature forms of $A$. aegypti near houses and in compounds in Trinidad, but no reference was made to localizations in natural environments.

In Iquitos (Peru), A. aegypti individuals were found only $10 \mathrm{~m}$ from containers with eggs, while in Puerto Rico, oviposition activity in the gonotrophic cycle covered an urban area of at least $840 \mathrm{~m}$ in diameter. In Kenya, the maximum distance traveled by females and males every $24 \mathrm{~h}$ was $154 \mathrm{~m}$ and $113 \mathrm{~m}$, respectively, and flights of greater distances have been recorded for variable proportions of the populations. Verdonshoot and BesseLototskaya (2012) reviewed the dispersion ability of approximately 100 mosquito species and considered that of $A$. aegypti to be very weak. Of the 5,062 immature forms of $A$. aegypti collected from tree holes in the west of Argentina, only nine larvae were found in a

Table 2. Intra-population genetic diversity measures for each sample.

\begin{tabular}{|c|c|c|c|c|c|c|c|}
\hline Samples & Molecular markers & $\mathbf{N}$ & Hd & NS & h & $\mathbf{K}$ & II \\
\hline Aedes aegypti (Sylvatic) & Cyt B & 17 & 0.11765 & 2 & 2 & 0.23529 & 0.00043 \\
\hline Aedes aegypti (Laboratory) & & 13 & 0.15385 & 2 & 2 & 0.30769 & 0.00057 \\
\hline Aedes aegypti (Sylvatic) & DNA Barcode & 14 & 0.27473 & 6 & 3 & 0.97802 & 0.00190 \\
\hline Aedes aegypti (Laboratory) & & 16 & 0.32500 & 4 & 2 & 1.30000 & 0.00252 \\
\hline
\end{tabular}

N: sample size; HD: Haplotypic diversity; NS, Number of polymorphic sites; $h$, Haplotype; $K$, average number of nucleotide difference; $\pi$ : Nucleotide diversity. 
tree hole in a secondary forest at a distance of $300 \mathrm{~m}$ from the urban border (Mangudo et al. 2015). These and other potential breeding sites in RPPNBR need to be examined.

Our findings on oviposition by A. aegypti not associated with human beings and humanmodified environments in primary forests in Rio de Janeiro are of serious concern. The presence of sylvatic populations of potential vectors constitutes an additional risk of transmission of arboviruses from the forest to its adjacent environments. The co-existence of A. aegypti and A. albopictus, ubiquitous species in Brazil, is certainly important considering the risk of reintroduction of the yellow fever (YF) virus in cities infested by A. aegypti. $\mathrm{YF}$, which originally occurred in Africa and was introduced into the American continent by trading and slave ships, was widely distributed from Baltimore to Argentina. It was controlled in all urban areas but persisted in sylvatic environments and was vectored by Haemagogus and Sabethes mosquitoes (Vasconcelos 2003). The presence of $A$. aegypti in sylvatic environments, co-existing with Haemagogus and possibly Sabethes spp., enhances the chances of the transmission of several arboviruses. Haemagogus leucocelaenus and H. janthinomys, important vectors of the YF virus, had also previously been found in ovitraps installed in RPPNBR (Alencar et al. unpublished), similar to the results of the present study.

Dengue, with four serotypes occurring in several areas, is transmitted by A. aegypti in urban areas and thus, the potential emergence of a sylvatic DEN-2 serotype is considered viable. Sylvatic transmission, reinforced by the findings of $H$. leucocelaenus infected with DEN-1 in the state of Bahia and infected sylvatic mammals of several species in French Guiana, has been suspected on the American continent (Marcondes and Tauil 2011). The Zika and Chikungunya viruses, recently introduced into Brazil and several American countries, have several sylvatic vectors, mostly Aedes (Stegomyia) spp., on other continents (Marcondes and Ximenes 2016). The existence of sylvatic populations of A. aegypti enhances the risk of these viruses adapting to preserved environments and other mosquitoes. Dengue and Zika viruses have already been found in monkeys in the New World, namely Puerto Rico and the Brazilian state of Ceará, respectively.

In Brazil, control of dengue transmission through the reduction of $A$. aegypti breeding sites has achieved little success and the occurrence of urban transmissions of YF is considered a risk in the future. Since $A$. aegypti has been mostly restricted to urban areas, its efficient control in these areas could theoretically reduce the transmission of the dengue virus and prevent the occurrence of YF. However, if $A$. aegypti adapted to sylvatic conditions, as it did in Senegal (Huber et al. 2008), it would be immensely difficult to control these mosquitoes as well as the circulation of viruses between forests and urban areas.

\section{Conflict of interest/Funding}

The authors acknowledge the financial support received from Fundação de Amparo à Pesquisa do Estado do Rio de Janeiro, FAPERJ (26/010.001630/2014; E-26/202.819/2015) and Conselho Nacional de Desenvolvimento Científico e Tecnológico-CNPq (301345/2013-9). The authors declare no conflict of interest.

\section{Authors' contributions}

JA, CFM, CBM and CBM planned the development of the research, collected and reared mosquitoes and helped in the preparation of manuscript; DAM collection and identification of mosquitoes, and data analysis; VQB and MTSF defined the molecular protocol. All authors revised and approved the various drafts. 


\section{References}

Altschul SF, Gish W, Miller W, Myers EW, Lipman DJ. 1990. Basic local alignment search tool. Journal of Molecular Biology. 215:403-410.

Consoli RAGB, Lourenço-de-Oliveira R. 1993. Principais mosquitos de importância médica no Brasil. Rio de Janeiro: Fiocruz. 228 pp.

Consoli RAGB, Lourenço-de-Oliveira R. 1994. Principais mosquitos de importância sanitária no Brasil. Rio de Janeiro: Fiocruz. 225 pp.

Hebert PDN, Cywinska A, Ball SL, Waard JR. 2003. Biological identifications through DNA barcodes, Proceedings of the Royal Society B: Biological Sciences. 270(11512):313-321.

Huber K, Ba Y, Dia I, Mathiot C, Sall AA, Diallo M. 2008. Aedes aegypti in Senegal: genetic diversity and genetic structure of domestic and sylvatic populations. American Journal of Tropical Medicine Hygiene. 79:218-229.

Lourenço-de-Oliveira R, Castro MG, Braks MAH, Lounibos LP. 2004. The invasion of urban forest by dengue vectors in Rio de Janeiro. Journal of Vector Ecology. 29:94-100.

Mangudo C, Aparicio JP, Gleiser RM. 2015. Tree holes as larval habitats for Aedes aegypti in urban, suburban and forest habitats in a dengue affected area. Bulletin of Entomological Research. 105:679-684.

Marcondes CB, Tauil, PL. 2011. Sylvatic dengue: should we be worried? Revista da Sociedade Brasileira de Medicina Tropical. 44:263-264.

Marcondes CB, Ximenes MFFM. 2016. Zika virus in Brazil and the danger of infestation by Aedes (Stegomyia) mosquitoes. Revista da Sociedade Brasileira de Medicina Tropical. 49:4-10.

Massad E, Burattini MN, Coutinho FAB, Lopez LF. 2003. Dengue e risco da reintrodução da febre amarela urbana no Estado de São Paulo. Revista de Saúde Pública. 37:477-484.

Rozas J, Sánches-Delbarrio JC, Messeguer X, Rozas R. 2003. Dna SP, DNA polymorphism analyses by the coalescent and other methods. Bioinformatics. 19:2496-2497.

Tamura K, Peterson D, Peterson N, Stecher G, Nei M, Kumar S. 2011. Mega5: Molecular evolutionary genetics analysis using maximum likelihood, evolutionary distance, and maximum parsimony methods. Molecular Biology and Evolution. 28:2731-2739.

Vasconcelos PF. 2003. Febre amarela. Revista da Sociedade Brasileira de Medicina Tropical. 36: 275-293.

Verdonschot PFM, Besse-Lototskaya A. 2012. Flight distance of mosquitoes (Culicidae): A metadata analysis to support the management of barrier zones around rewetted and newly constructed wetlands. Limnologica. Ecology and Management of Inland Waters. 45:69-79.

Wastika CE, Sasaki M, Yoshii K, Anindita PD, Hang'ombe BM, Mweene AS, Kobayashi S, Kariwa H, Carr MJ, Hall WW, Eshita Y, Orba Y, Sawa H. 2019. Serological evidence of Zika virus infection in non $\square$ human primates in Zambia. Archives of Virology. 164:2165-2170.

Ximenes MFF, Galvão JMA, Inacio CLS, Macêdo-e-Silva VP, Pereira RLN, Pinheiro MPG, Siva MMM, Gomes CES. 2020. Arbovirus expansion: new species of culicids infected by the Chikungunya virus in an urban park of Brazil. Acta Tropica. 209(05538):1-5.

Zhao L, Pridgeon JW, Becnel JJ, Clark GG, Linthicum KJ. 2009. Mitochondrial gene Cytochrome b developmental and environmental expression in Aedes aegypti (Diptera: Culicidae). Journal of Medicinal Entomology. 46:1361-1369.

This article is distributed under the terms of the Creative Commons Attribution Noncommercial License (by-nc 4.0) which permits any noncommercial use, distribution, and reproduction in any medium, provided the original author(s) and source are credited. 